\title{
ANAESTHESIA AND THE RESPIRATORY SYSTEM
}

\author{
KaI Rehder
}

UNDERSTANDING OF THE MECHANISMS that contribute to the impaired gas exchange that frequently follows the induction of general anaesthesia involves many areas. These areas include the effects of anaesthesia on intrapulmonary gas distribution, the mechanical properties of the lung and chest wall, the functional residual capacity, the shape and motion of the chest wall, and the ventilation-perfusion relationships.

\section{Evidence For}

impaired Pulmonary Gas Exchange

In measurements of right-1o-left shunt (QS/Q்T) and venous admixture (QVA/Qr) during anaesthesia, representative studies have reported intrapulmonary right-to-left shunts ranging from 6 to 14 per cent of the total cardiac output (Table I). These values are higher than those reported for awake normal man, in whom shunts have ranged from two to four per cent of the cardiac output. Nunn ${ }^{1}$ and Price, et al. ${ }^{6}$ reported venous admixture larger than right-to-left shunt.. Venous admixture represents the combined effects of right-to-left shunting and mismatching of ventilation to perfusion. Thus, during general anaesthesia, both increased right-to-left shunting and increased mismatching of ventilation to perfusion contribute to the inefficiency of oxygenation. However, the methods used in these studies may have affected the relative contribution of shunt and ventilation-to-perfusion mismatching.

Physiological dead space is the sum of anatomical and alveolar dead space. Alveolar dead space represents ventilation of lung regions with $\dot{V}_{A} / Q$ ratios higher than the overall $\dot{V}_{A} / Q$. including regions with $\dot{V}_{A} / Q$ ratios of infinity. In awake normal man, alveolar dead space is virtually nonexistent. Most investigators found a substantial alveolar dead space after induction of

Kai Rehder, M.D., Departments of Anesthesiology, Physiology and Biophysics, Mayo Clinic. Rochester. Minnesota 55901, U.S.A.

Presented as the Annual Royal College Lecture at the Annual Meeting of the Canadian Anaesthetists' Society, Edmonton, Alberta, June 17-20, 1979.

This investigation was supported in part by Public Health Service grants HL-21584 and RR-585. Bethesda, Maryland, U.S.A anaesthesia (Table II). Thus, increased mismatching of ventilation to perfusion during general anaesthesia causes impaired carbon dioxide elimination.

\section{EfFect of ANaEsthesia-Paralysis and MECHanical VENTILATION}

On Intrapulmonary Inspired Gas Distribution. What are the mechanisms for this increased mismatching of ventilation to perfusion? Even in normal man, distributions of inspired gas and pulmonary capillary blood flow are not totally uniform throughout the lung; that is, there is some mismatching of ventilation to perfusion. The non-uniform distribution of inspired gas has been ascribed to a vertical gradient in pleural pressure, ${ }^{13}$ while the non-uniform distribution of pulmonary capillary blood flow has been shown to be primarily due to the effect of gravity. ${ }^{14}$

John Snow's pointed out as early as 1858 that inhalation of chloroform led to breathing "... sometimes performed only by the diaphragm whilst the intercostal muscles are paralyzed." Because of the altered motion of the chest wall. we assumed that intrapulmonary gas distribution may be altered during anaesthesia. Hence, we concentrated in our first studies on comparing intrapulmonary inspired gas distribution between the awake and anaesthetized-paralyzed states.

Intrapulmonary gas distribution in healthy young volunteers was examined using a modified single-breath oxygen $\left(\mathrm{SBO}_{2}\right)$ test. ${ }^{16}$ With the subject awake and breathing spontaneously, a large increase in expired nitrogen concentration was observed during the so-called alveolar plateau (phase III) (Figure 1). Superimposed on the alveolar plateau and synchronous with the heart beat were large variations in expired nitrogen concentration. These are called cardiogenic oscillations. The progressive increase in expired nitrogen concentration of the alveolar plateau is believed to be due to a non-uniform distribution of inspired gas in conjunction with asynchronous emptying of the lung. Relatively well-ventilated lung regions in which the resident nitrogen is most diluted by the inspired oxygen empty first. As exhalation continues, relatively poorly venti- 
TABLE I

Right-to-Left Shunt and Venous Admixture in ANaesthetized Man

\begin{tabular}{|c|c|c|c|c|}
\hline Author & $\begin{array}{l}\text { Age } \\
(\mathrm{yr})\end{array}$ & $\begin{array}{c}\text { Type of } \\
\text { ventilation }\end{array}$ & $\underset{(\%)}{Q s / Q \tau}$ & $\begin{array}{c}\text { QVA/QT } \\
(\%)\end{array}$ \\
\hline Nunn' & 51 & Spontaneous & 14 & 21 \\
\hline Nunn, ef $a l^{2}$ & $\$ 1$ & $\begin{array}{l}\text { Mechanical } \\
\text { ventilation }\end{array}$ & 11 & 9 \\
\hline Michenfelder, et $a l^{3}$ & - & $\begin{array}{l}\text { Mechanical } \\
\text { ventilation }\end{array}$ & 14 & 10 \\
\hline Bergman ${ }^{4}$ & 48 & $\begin{array}{l}\text { Mechanical } \\
\text { ventilation }\end{array}$ & 11 & 10 \\
\hline Marshall, et al.s & 41 & Spontaneous & 12 & - \\
\hline Price, et al.6 & $21-27$ & $\begin{array}{l}\text { Spontaneous } \\
\text { Mechanical } \\
\text { ventilation }\end{array}$ & $\begin{array}{r}6 \\
11\end{array}$ & $\begin{array}{l}19 \\
15\end{array}$ \\
\hline Marsh, et al..$^{7}$ & 28 & $\begin{array}{l}\text { Mechanical } \\
\text { ventilation }\end{array}$ & 6 & - \\
\hline
\end{tabular}

TABLE II

Alveolar and Physiological Dead Space in Anaesthetized Man

\begin{tabular}{|c|c|c|c|c|c|}
\hline Author & $\begin{array}{l}\text { Age } \\
(y r)\end{array}$ & $\begin{array}{c}\text { Type of } \\
\text { ventilation }\end{array}$ & $\begin{array}{r}V_{T} \\
(\mathrm{ml})\end{array}$ & $\begin{array}{c}\text { Vo alv } \\
\text { (mi) }\end{array}$ & $\begin{array}{l}\text { Vo phys } \\
\text { (ml) }\end{array}$ \\
\hline Campbell $^{8}$ & 31 & $\begin{array}{l}\text { Mechanical } \\
\text { ventilation }\end{array}$ & 423 & - & 203 \\
\hline \multirow[t]{2}{*}{ Nunn and Hill' } & 35 & $\begin{array}{l}\text { Mechanical } \\
\text { ventilation }\end{array}$ & 474 & 91 & 153 \\
\hline & 35 & Spontaneous & 245 & 43 & 78 \\
\hline Askrog, et $a l^{10}$ & 54 & $\begin{array}{l}\text { Mechanical } \\
\text { ventilation }\end{array}$ & 575 & 66 & 210 \\
\hline Kain, et al.' & 42 & Spontaneous & 263 & - & 132 \\
\hline Rehder, et al.12 & 26 & $\begin{array}{l}\text { Mechanical } \\
\text { ventilation }\end{array}$ & 643 & 61 & 134 \\
\hline
\end{tabular}

lated regions in which the resident nitrogen is less diluted contribute progressively more to the expirate. In these studies, the slope of the alveolar plateau was reduced after induction of anaesthesia-paralysis. Furthermore, the amplitude of the cardiogenic oscillations was reduced. The reduction in slope of the alveolar plateau indicates a more uniform inspired gas distribution or a more synchronous emptying of the lung. or both.

In an attempt to discern which of these possibilities produced the changes in the slope of the alveolar plateau, multiple-breath oxygen tests were performed, ${ }^{16}$ first in the awake and then in the analesthetized-paralyzed state. In this test, expired nitrogen concentration and expired flow rate are recorded simultaneously for each suc. cessive breath after the inspired gas mixture is

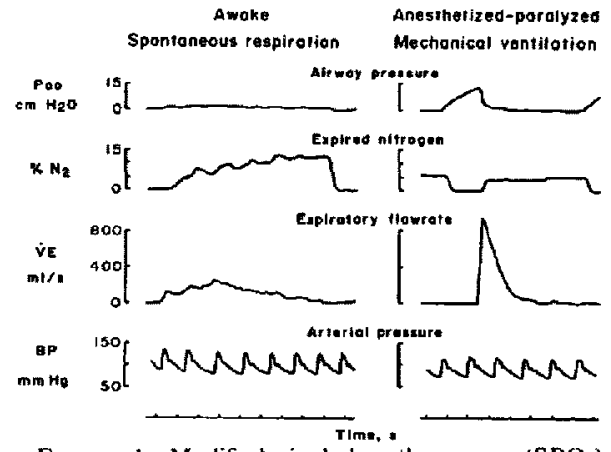

Figure 1 Modified single-breath oxygen $\left(\mathrm{SBO}_{2}\right)$ test in a subject studied while in right lateral decubitus position. Note difference in slope of phase III and in amplitude of cardiogenic oscillations of alveolar plateau after induction of anaesthesia-paralysis. 


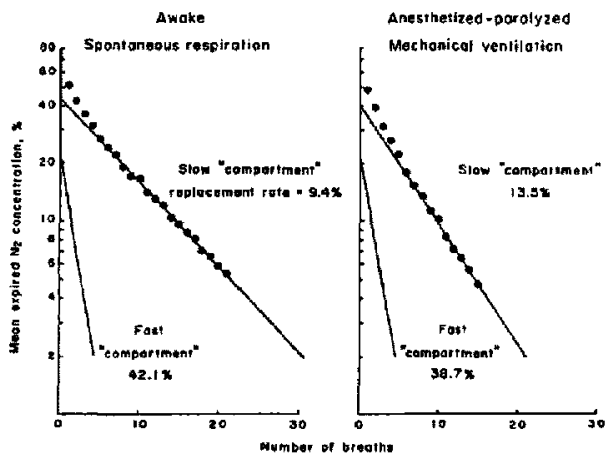

Fioure 2 Multiple-breath oxygen test in a subject studied while in right lateral decubitus position. Difference in nitrogen clearance rates between slow and fast "compartments" was less in anaesthetized-paralyzed than in awake state, indicating a more uniform distribution of inspired gas.

changed from room air to 100 per cent oxygen. The mean expired nitrogen concentration is then calculated for each breath and is plotted on semilogarithmic paper as a function of the number of breaths (Figure 2). The resulting plot is usually curvilinear, indicating that the pulmonary nitrogen clearance is not a single but a multiexponential function; that is, intrapulmonary inspired gas distribution is not uniform. Two or three exponentials can be graphically derived from the curvilinear relationship, thus dividing the lung into two to three functional but not anatomical compartments with different nitrogen clearance rates. The clearance rates of the two functional compartments were more similar during anaesthesia-paralysis than during awake spontaneous breathing, thus suggesting that intrapulmonary inspired gas distribution had become more uniform.

The function of each lung was examined separately to gain insight into the reason for the intrapulmonary inspired gas distribution becoming more uniform with the subject in the lateral decubitus position. ${ }^{17}$ To do this, nitrogen clearances of the two lungs were measured simultaneously but separately, and the results were compared with those obtained in normal awake and spontaneously breathing subjects. ${ }^{18}$ In both the awake and anaesthetized-paralyzed states, the nitrogen clearance of the dependent lung was faster than that of the non-dependent lung (Figure 3). The nitrogen clearances of the two lungs were more similar in the anaesthetized-paralyzed than in the awake state; that is, intrapulmonary in-

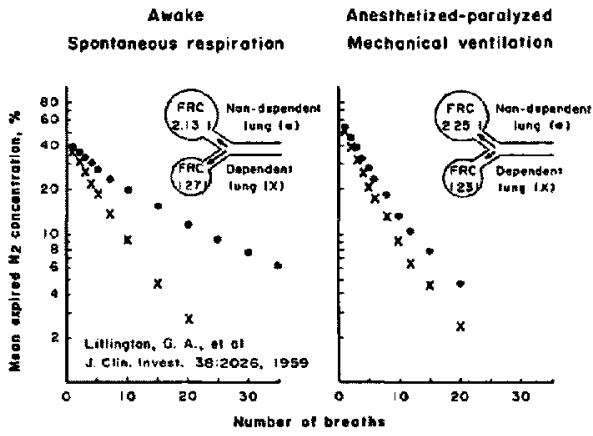

Figure 3 Multiple-breath oxygen test of subject studied while in right lateral decubitus position. Nitrogen clearance curves for dependent $(X)$ and non-dependent $(O)$ lungs were calculated from mean data. Dependent lung cleared its pulmonary nitrogen faster in both states, buf clearance rates were more similar between the two lungs in anaesthetized-paralyzed state. This represents a more uniform gas distribution during anaesthesia-paralysis. (From Rehder, et at. ${ }^{7}$ By permission of J. B. Lippincott Company.)

spired gas distribution was more uniform during anaesthesia-paralysis. The nitrogen clearance rates of the two lungs were more similar because the relative distribution of tidal volume was altered, while the relative volumes of the two lungs had remained unchanged.

The question then became, why was the distribution of tidal volume altered during anaesthesia-paralysis and mechanical ventilation of the lungs? Distribution of inspired gas between the two lungs depends on the distribution of the expanding forces for each lung and on the differences in admittance to the two lungs.

The distribution of the expanding forces will be considered first. The pleural pressure is more subatmospheric at the non-dependent and less subatmospheric at the dependent region (Figure 4). Because alveolar pressure is uniform throughout the lung, the expanding pressure for the lung, that is, the transpulmonary pressure, is larger at the non-dependent than at the dependent region. If the non-dependent and dependent lung regions have the same elastic properties, that is, if their pressure-volume (P-V) relationships were similar. regional lung volumes would be different: non-dependent regions would be more expanded than dependent regions. If the expanding pressure were to increase during inspiration by the same amount in both regions, larger lung volume changes would occur in the dependent than in the non-dependent regions. 


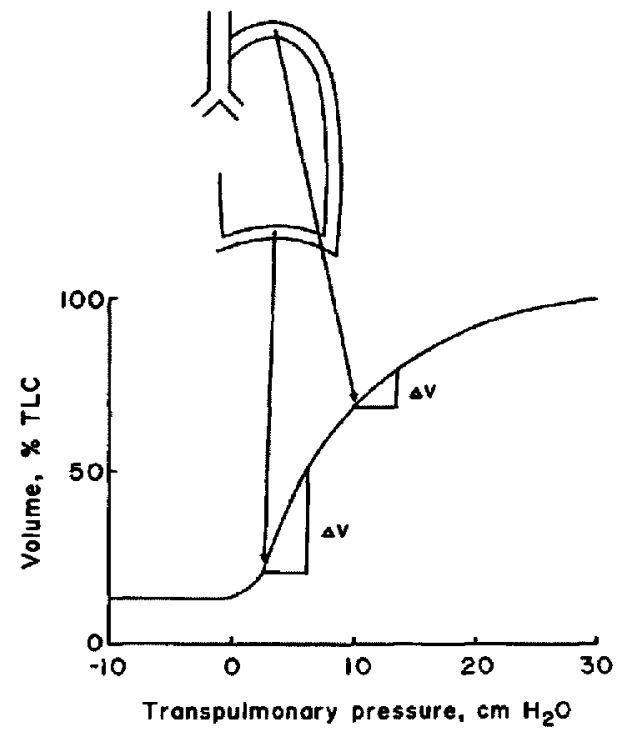

Figure 4 Vertical pleural pressure gradient and intrapulmonary gas distribution. Pleural pressure is more subatmospheric at apex than at base of lung in erect subject. This results in a larger expansion of apical than basal alveoli.

This model explains the non-uniform gas distribution occurring in normal man as a result of the observed vertical pleural pressure gradient. More recent studies suggest that the vertical pleural pressure gradient may have a more complex origin and result from, rather than causing. the non-uniform distribution of inspired gas. ${ }^{19}$ The isolated lung and thoracic wall will adopt different shapes at a given volume with a uniform distending pressure. This shape is called the natural shape. For example, the lung may, in its natural shape, be smaller than the thoracic wall at the apex and larger at the base (Figure 5 ). In vivo the two structures must conform one to the other; that is, at the apex. the lung would have to expand while the thoracic wall would have to become smaller. At the base, the reverse would have to occur; the lung would become smaller while the thoracic wall would expand. Another major force contributing to the deformation from the natural shape is the force of gravity. These deformations of lung and thoracic wall would alter the vertical distribution of regional lung volume, inspired gas, and pleural pressure. According to this latter theory, the deformations are responsible for the vertical pleural pressure gradient.

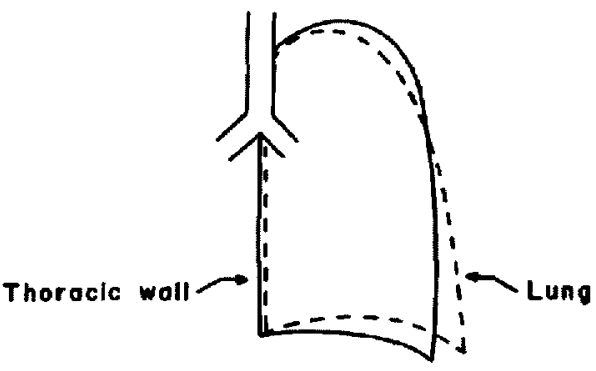

FICURE 5 Diagrammatic representation of natural shapes of lung and chest wall. (From Macklem, P.T. \& Murphy, B. The forces applied to the lung in health and disease. Am. J. Med. 57: 371 (1974). By permission of Dun-Donnelley Publishing Corporation.)

To examine the vertical distributions of regional lung volumes and inspired gas directly and by implication, the vertical pleural pressure gradient before and during anaesthesia-paralysis. studies using ${ }^{133}$ xenon were done. ${ }^{20}$ In the right lateral decubitus position, the vertical gradient in regional lung volumes at FRC was greater during anaesthesia-paralysis than during the awake state; that is, the non-dependent alveoli were larger and the dependent alveoli smaller (Figure 6). This observation indicates that the shape of the respiratory system at FRC was altered by anaesthesia and paralysis of the respiratory muscles. An alteration of the shape of the respiratory system at FRC also had been directly observed by Froese and Bryan. ${ }^{21}$ They demonstrated that induction of anaesthesia, with or without paralysis, altered the end-expiratory or resting

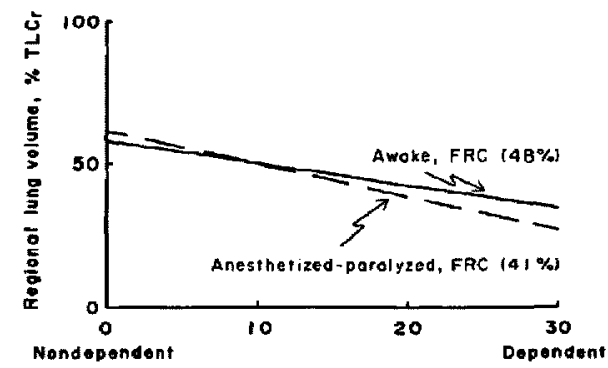

Vertical distance down the lung $(0), \mathrm{cm}$

Figure 6 Regional lung volumes of subjects studied while in lateral decubitus position. Note increase of regional lung volume in non-dependent and decrease in regional lung volume in dependent lung after induction of anaesthesia-paralysis. 


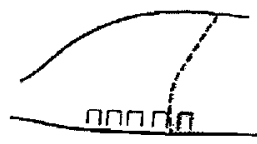

AWAKE SPONTANEOUS
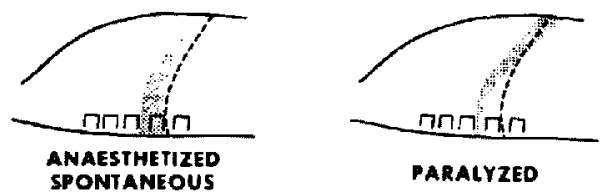

FIGURE 7 Position and displacement of diaphragm during tidal breathing in supine subject. Dashed lines represent awake functional residual capacity position of diaphragm. Stippled areas represent diaphragmatic excursion during tidal breathing. (From Froese \& BRYAN." By permission of J. B. Lippincott Company.)

position of the diaphragm; that is, the diaphragm moved cephalad, particularly in dependent regions (Figure 7).

On Mechanical Properties. Impedance is the total opposition to gas flow into the lungs. Therefore, impedance consists of elastic, flowresistive, and inertial forces. Inspired gas distribution may be altered when the distributions of these elastic, flow-resistive, or inertial forces within the respiratory system are changed.

The elastic forces of the lung and chest wall were assessed before and during anaesthesiaparalysis in healthy young subjects by determining the static P-V relationships. ${ }^{22}$ Anaesthesia shifted the P-V curve of the total system to the right and decreased the slope of this P.V curve (Figure 8). The shift to the right means that the
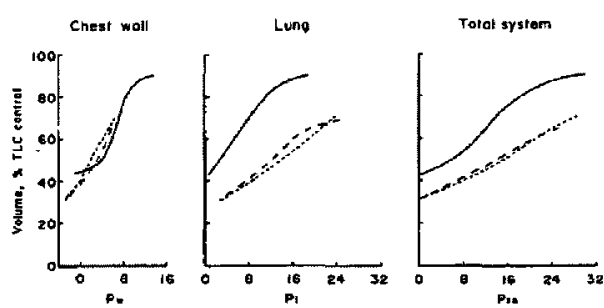

Figure 8 Mean pressure-volume curves of chest wall, lung, and total respiratory system. Note marked shift to right of $P$-V curves of lung and total system after induction of anesthesia. No further change occurred with muscle paralysis. (From WEstBrook, ef al. ${ }^{22}$ By permission of the American Physiological Society.)
RC TIME CONSTANT

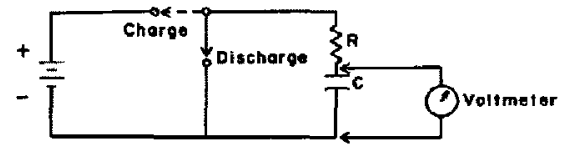

RATE OF DISCHARGE OF RC SYSTEM

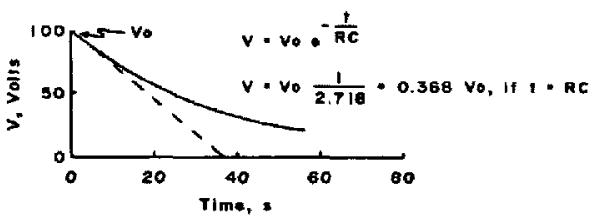

Figure 9 Electric circuit consisting of resistor $(R)$ and capacitor $(C)$. Decline of voltage during discharge of capacitor is plotted as a function of time. Voltage at any time during discharge can be calculated from for* mula: $\mathrm{V}=\mathrm{V}_{0} \times \mathrm{e}^{-\mathrm{ukC}}$. If $\mathrm{t}=\mathrm{RC}$, the formula reduces to $v=V_{0} \times 1 / 2.718=0.368 V_{0}$. The product of $R$ and $C$ is the time constant of the system, that is, the time necessary to discharge the capacitor to 36.8 per cent of its original voltage.

recoil pressure was increased; that is, during anaesthesia-paralysis, a greater inflating pressure was required to achieve a given lung volume. For example, at a lung volume equivalent to 50 per cent of control total lung capacity (TLC), the airway pressure averaged $6.3 \mathrm{~cm} \mathrm{H}_{2} \mathrm{O}$ in awake subjects and $15.8 \mathrm{~cm} \mathrm{H}_{2} \mathrm{O}$ during anaesthesia. The reduction in slope of the $\mathrm{P}-\mathrm{V}$ relationship during anaesthesia indicates a reduction in the compliance of the total system; that is, a larger pressure change is necessary for a given volume change. The shift of the P-V curve of the total system was associated with a similar shift of the P-V curve of the lung. At $\mathbf{5 0}$ per cent control TLC, the expanding pressure for the lung increased from $2.8 \mathrm{~cm} \mathrm{H}_{2} \mathrm{O}$ during the awake state to $12.2 \mathrm{~cm} \mathrm{H}_{2} \mathrm{O}$ during the anaesthetized state. The compliance of the lung was also reduced. The P-V curve of the chest wall tended to shift to the left at higher volumes and to the right at lower volumes. Thus, anaesthesia has a pronounced effect on the elastic properties of the respiratory system and its components, the lung and chest wall. Paralysis did not cause any further significant changes in these elastic properties.

The mechanics of the respiratory system can be conveniently compared to a simple electric analog consisting of a linear resistor $(R)$ and capacitor (C), arranged in series (Figure 9 ). If the 


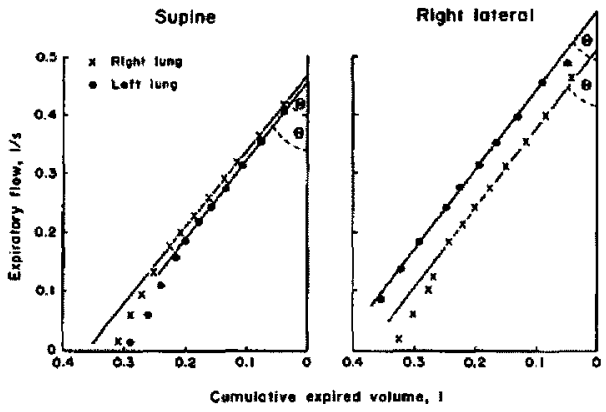

Figure 10 Flow-volume curves of individual hemithoraces of subjects studied in supine or right lateral decubitus positions. The slope of these lines can be considered the time constant of the individual hemithorax. The slope can be obtained by the tangent of the angle $B$ subtended to a perpendicular drawn to $x$-axis.

rate of decrease in voltage from a charged capacitor in such a circuit is plotted as a function of time, the voltage decays in an exponential fashion. The time constant (t) for discharge of such an $R C$ circuit equals the product of $R$ and $C$. By analogy, if the expiratory flow is plotted as a function of expired volume during a passive exhalation, the time constant of the respiratory system can be determined from the slope of this relationship. This time constant is the product of resistance and compliance of the respiratory system. Time constants for the left and right hemithoraces were determined from the slope of flow-volume curves for the individual lungs oblained during bronchospirometric studies in anaesthetized-paralyzed subjects ${ }^{17}$ (Figure 10). These time constants were similar for both lungs in subjects in the supine and right lateral decubitus positions. Compliances of the left and right hemithoraces were also similar in the supine position but not in the right lateral decubitus position, for which the compliance of the right or dependent hemithorax was less than that of the left or non-dependent hemithorax. After the compliances have been measured and the time constants of the two hemithoraces estimated, the resistances of the two hemithoraces can be calculated by dividing the time constant over the compliance. Although the resistances of the two hemithoraces differed considerably in the lateral positions, calculated end-inspiratory alveolar pressures increased to approximately the same extent in both lungs, because the time allowed for filling was considerably longer than the greatest estimated time constant. Since the inertial forces

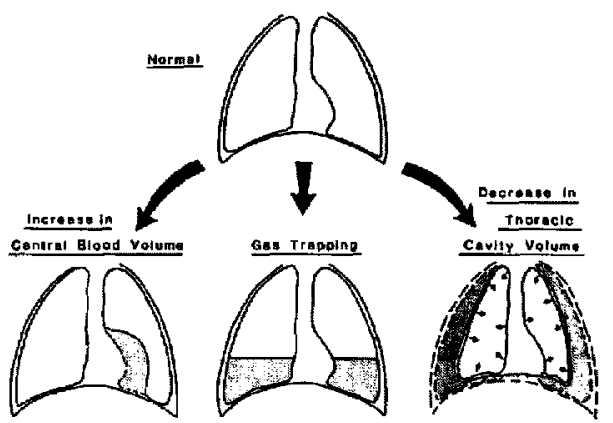

Figure II Possible mechanisms for reduction of FRC after induction of anaesthesia-paralysis.

of the respiratory system are small and can be ignored, the measured differences of respiratory compliances between the two hemithoraces can be considered to be the primary mechanical force responsible for the altered distribution of inspired gas between the two lungs with the subject in the lateral decubitus position.

On Functional Residual Capacity.

Reductions in FRC in recumbent subjects after induction of anaesthesia have been observed by many investigators. ${ }^{23}$ Several mechanisms may be responsible or contribute to the reduction in FRC (Figure 11). An increase in central blood volume could reduce thoracic gas volume. There is currently no experimental proof that this occurs. Gas trapping behind closed airways could result in an apparent reduction of FRC when measured by gas dilution or clearance. However. it is unlikely to be a major contributing factor. because similar reductions in FRC were also found by body plethysmography. ${ }^{22}$ Another possible mechanism for the reduction in FRC is a reduction in thoracic cavity volume. This could be caused by a reduction in the outward recoil of the chest wall. At FRC, the elastic recoil pressures of lung and chest wall are equal but opposite in sign, so that they cancel each other (Figure 12). A decreased outward recoil of the chest wall. that is, a shift to the right of the P-V curve, would result in a reduction of FRC if the lung $P$ - $V$ curve remained unchanged. Conversely, an increase in recoil pressure of the lung with an unchanged $P$-V curve for the chest wall would also decrease FRC.

To examine whether FRC was reduced by the increased recoil pressure of the lung or by a change in the P-V curve of the chest wall. a pressure-volume curve (Pes) was drawn which represented the normal elastic behaviour of the 

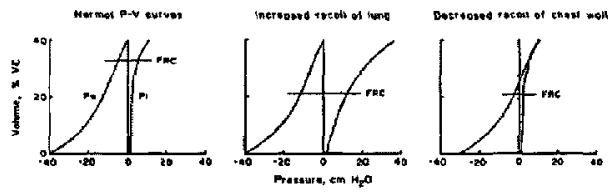

FIGURE 12 Mechanisms affecting FRC At FRC. the elastic recoil pressures of lung and chest wall are equal in size but opposite in sign. that is. they cancel each other. An increased recoil of the lung (P-V curve shifted to the right) without appropriate change of the recoil of the chest wall or a decreased recoil of the chest wall (P-V curve shifted to the right) without appropri" ate change of the recoil of the lung results in a reduction of FRC.

chest wall of a supine awake subject (Figure 13). The static recoil pressures for lung, which would be required if FRC were to decrease without a change in the P-V curve of the chest wall, were estimated. These recoil pressures for the lung would exactly cancel the recoil pressure of the chest wall and are therefore shown as a mirror image of this curve (PI). The five closed circles indicate the elastic recoil pressures of the lung measured in the five anaesthetized supine subjects at FRC. These elastic recoil pressures are much lower than the predicted necessary recoil for the lung if the P.V curve of the chest wall had not changed during anaesthesia. In the five subjects, the recoil pressure of the lung was estimated from the difference between cesophageal and airway pressures. Because recoil pressures estimated from oesophageal pressures in supine subjects tend to underestimate the true recoil pressure, an under-estimation of $7 \mathrm{~cm} \mathrm{H}_{2} \mathrm{O}$ was

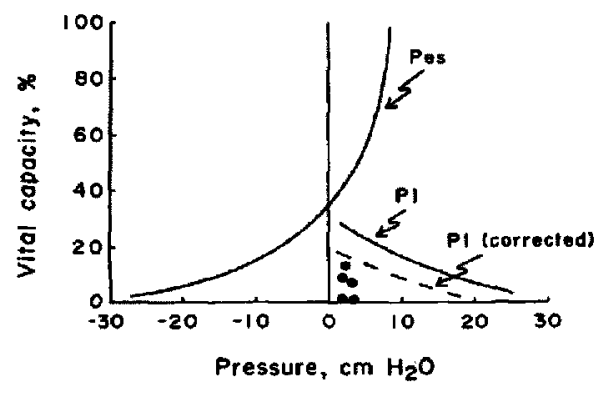

Figure 13 Pressure-volume curve (Pes) representing normal elastic behavior of chest wall of a supine awake subject. Elastic recoil pressures of lung (PI) which would be required if lung volume were to change without a change in P.V curve of chest wall. (From WestrRook, et $a .^{22}$ By permission of the American Physiological Society.)
TABLE 1II

Effect of anaesthesia-Paralysis on Functional Residual Capacity (FRC) and Lung Compliance $\left(C L_{\text {dyn }}\right)$ in Sitting MaN (MEAN $\pm S E$ )

\begin{tabular}{lcc}
\hline \multicolumn{1}{c}{ Variable } & Awake & $\begin{array}{c}\text { Anaesthetized- } \\
\text { paralyzed }\end{array}$ \\
\hline FRC (litres) & $3.26 \pm 0.26$ & $3.29 \pm 0.24$ \\
${\left.\text { CL dy (litres } / \mathrm{cm} \mathrm{H}_{2} \mathrm{O}\right)}^{0.18 \pm 0.03}$ & $0.15 \pm 0.03$ \\
\hline
\end{tabular}

(From Rehder, et $a l^{24}$ )

estimated and a curve, labeled corrected PI, was drawn. The values for the anaesthetized subjects were still lower than this predicted and corrected curve. Therefore, the P-V curve of the chest wall probably moved to the right after induction of andesthesia-paralysis; that is, the outward recoil of chest wall at FRC was decreased during anaesthesia-paralysis.

Because the changes in the mechanical properties of the chest wall may be dependent on body position. FRC and dynamic lung compliance were determined before and after induction of anaesthesia-paralysis in sitting subjects. ${ }^{24} \mathrm{No}$ significant change in FRC nor in dynamic lung compliance occurred after induction of anaesthesia-paralysis in the sitting position (Table III). Thus, the reductions in FRC and lung compliance observed in recumbent subjects were not a direct effect of the anaesthetic on the lung, but rather an effect of anaesthesia-paralysis on the chest wall. an effect that is dependent on body position.

\section{Effect of anaesthesia On Shape and MOTION OF CHEST WALL}

Further evidence for an effect of anaesthesia on the chest wall has been produced by studies using magnetometers. If certain assumptions are fulfilled. magnetometers allow the determination of the relative contributions of the rib cage and diaphragm to a tidal breath. The rib cage contributes approximately $\mathbf{4 0}$ per cent to the total tidal volume in spontaneously breathing awake supine subjects ${ }^{25}$ (Table IV). Its contribution to the tidal volume is significantly reduced during anaesthesia and spontaneous breathing ${ }^{26} \mathrm{By}$ contrast. during anaesthesia and mechanical ventilation of the lung, the relative volume change resulting from motion of the rib cage is significantly increased. ${ }^{25}$ The rib cage motion with mechanical ventilation accounts for 74 per cent of tidal volume. The surface area of the visceral pleura in contact with the thorax constitutes about 72 per 
TABLE IV

Relative Contribution of Rib Cage to tidal Volume (Mean \pm SE)

\begin{tabular}{lccc}
\hline & & \multicolumn{2}{c}{ Anaesthetized } \\
\cline { 3 - 4 } Author & Awake & Spontaneous & $\begin{array}{c}\text { Mechanical } \\
\text { ventilation }\end{array}$ \\
\hline Grimby, et al..$^{25}$ & $40 \pm 5$ & - & $74 \pm 6$ \\
Tusiewicz, et al. ${ }^{26}$ & $43 \pm 4$ & $19 \pm 5$ & - \\
\hline
\end{tabular}

cent of the total pleural surface area. Thus, the motion of the rib cage during mechanical ventilation is consistent with a nearly uniform expansion of the lung.

The motion of the chest wall in anaesthetized dogs during spontaneous breathing and during mechanical ventilation of the lung was also considerably different ${ }^{27}$ (Figure 14). In some instances, there was an inward motion of the rib cage with inspiration during spontaneous

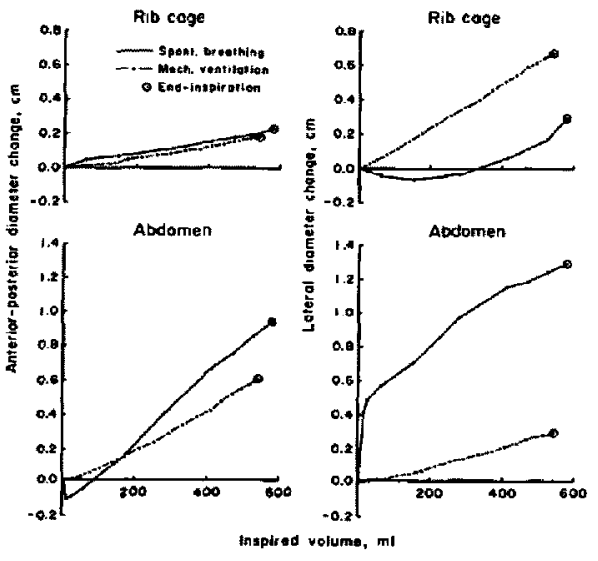

Figure 14 Motiun of chest wall in anaesthetized dogs in supine position. Note initial inward motion of lateral aspect of rib cage during spontaneous breathing (upper right-hand panel). (From SCHMID, ef al. ${ }^{27}$ )

breathing (Figure 14, upper right-hand panel). If present, the inward motion always disappeared with mechanical ventilation of the lungs.

Therefore, anaesthesia changes both the shape and the motion of the chest wall, and these changes may produce secondary changes in the mechanical properties of the lung; that is, they may decrease the compliance and increase the elastic recoil pressure of the lung and contribute to an altered distribution of inspired gas.

\section{EFFEct of ANaEsTHesia-Paral. YSIS AND}

MEChanical Ventilation ON

VENTILATION-PERFUSION RELATIONSHIPS

The efficiency of pulmonary gas exchange depends on the appropriate matching of gas and blood in the lung. ${ }^{133}$ Xenon was used to determine both the inspired gas and intrapulmonary blood flow distributions in healthy young volunteers breathing 100 per cent oxygen. ${ }^{20.29}$ After induction of anaesthesia and paralysis, inspired gas distribution became significantly more uniform in subjects in the right lateral decubitus and supine positions (Figure 15). By contrast, in subjects in the sitting position, gas distribution became less uniform, while there was little change

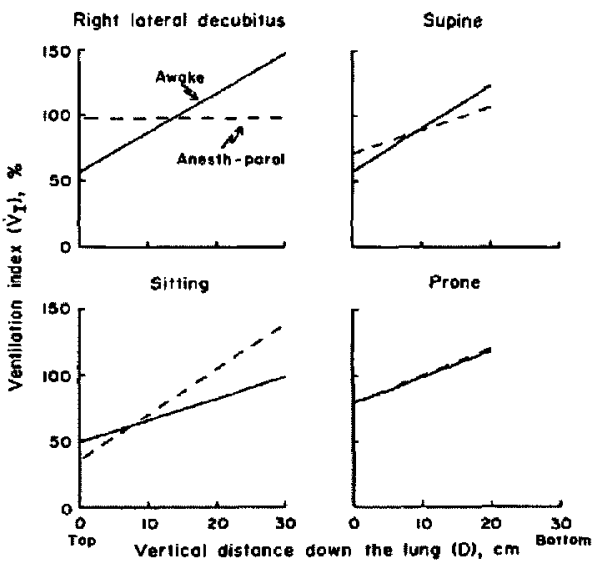

Flgure 15 Intrapulmonary inspired gas distribu tion (ventilation per unit lung volume) in four different body positions determined with 133 xenon. With anaesthesia-paralysis, gas distribution became nearly totally uniform in the right lateral decubitus and more uniform in the supine position (slope of lines decreased) and less uniform in the sitting position. In contrast. in the prone position, anaesthesia-paralysis had no effect on ventilation per unit lung volume. (From REHDER, $e$ al. ${ }^{28}$ By permission of the American Physiological Society.) 

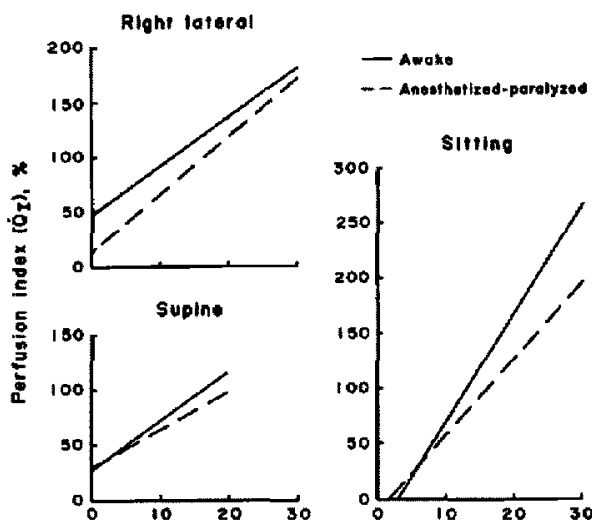

verilical distance down the lung $\{\mathrm{D}\}, \mathrm{cm}$

Figure 16 Intrapulmonaly distribution of blood flow at FRC determined with ${ }^{133}$ xenon in three body positions. With anaesthesia-paralysis, perfusion per unit lung volume became less uniform in the right lateral decubilus position (slope of line increased) and more uniform in the sitting position. In contrast, anaesthesia-paralysis had no significant effect on perfusion per unit lung volume in the supine position.

in those in the prone position. ${ }^{28}$ In none of the body positions that were examined was the distribution of pulmonary blood flow adjusted to the altered inspired gas distribution ${ }^{29}$ (Figure 16). In the right lateral position, blood flow distribution became less uniform during anaesthesia while, in the supine position, the changes were not significant. By contrast, in the sitting position, distribution of blood flow became more uniform after induction of anaesthesia-paralysis. In all positions, gravity appeared to be the major determinant of blood flow distribution both in the awake and anaesthetized-paralyzed states.

A small degree of mismatching of ventilation to perfusion was noted in awake and recumbent subjects (Figure 17). Induction of anaesthesiaparalysis increased the mismatching of ventilation to perfusion in the recumbent positions, but the increase was significant only for the right lateral decubitus position. In the sitting position, the change was not significant. An alveolararterial oxygen tension difference $(\mathrm{A}-\mathrm{a}) \mathrm{PO}_{2}$ of 9 $\mathrm{mm} \mathrm{Hg}(1.2 \mathrm{kPa})$ was estimated from the calculated distributions of regional ventilation-toperfusion ratios for sitting anaesthetized-paralyzed subjects. (A-a) $\mathrm{PO}_{2}$ values of similar magnitude were predicted for anaesthetized-paralyzed subjects in the lateral decubitus position. These $(\mathrm{A}-\mathrm{a}) \mathrm{PO}_{2}$ values, which do not include the

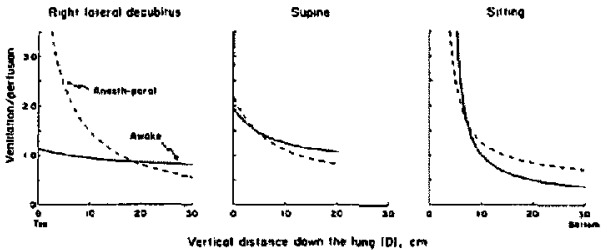

Figure 17 Regional distribution of ventilation to perfusion determined with ${ }^{133}$ xenon. Only in the right lateral decubitus position was mismatching of ventilation to perfusion significantly increased after induction of anaesthesia-paralysis.

contributions of right-to-left anatomic shunt, were considerably smaller than ( $\mathrm{A}-\mathrm{a}) \mathrm{Po}_{2}$ values measuredduringanaesthesia-paralysis. ${ }^{7}$ This suggests that mismatching of ventilation to perfusion alone could not completely explain the increased (A-a) $\mathrm{PO}_{2}$ seen during general anaesthesia. However, estimations of ventilation-to-perfusion mismatching from ${ }^{133}$ xenon data may be too low. because intraregional differences in the relationship of ventilation to perfusion may not be detected.

Therefore, the matching of ventilation to perfusion and of right-to-left intrapulmonary shunt was determined before and during anaesthesiaparalysis using the "inert" gas elimination method. This method has the advantage that it does not necessitate the use of 100 per cent oxygen breathing, which in itself may cause an increase in right-to-left shunting. A consistent increase was noted in mismatching of ventilation to perfusion after induction of anaesthesia-paralysis in subjects who were in the supine or right lateral decubitus positions ${ }^{12}$ (Figure 18). Lung regions with ventilation-to-perfusion ratios that were both low and high developed. Small right-to-left intrapulmonary shunts developed after induction of anaesthesia-paralysis. These shunts were lower than the values reported in Table $I$, in part because the anatomical right-to-left shunt was not included in this measurement and in part. perhaps, because these subjects were not breathing 100 per cent oxygen. A third important finding was the development of lung regions with high ventilation-to-perfusion ratios which contributed to the alveolar dead space after induction of anaesthesia-paralysis (Table II).

Right-to-left intrapulmonary shunting may theoretically increase during oxygen breathing. ${ }^{30}$ This possibility was examined by comparing the distributions of ventilation and perfusion relative to ventilation-to-perfusion ratios during 

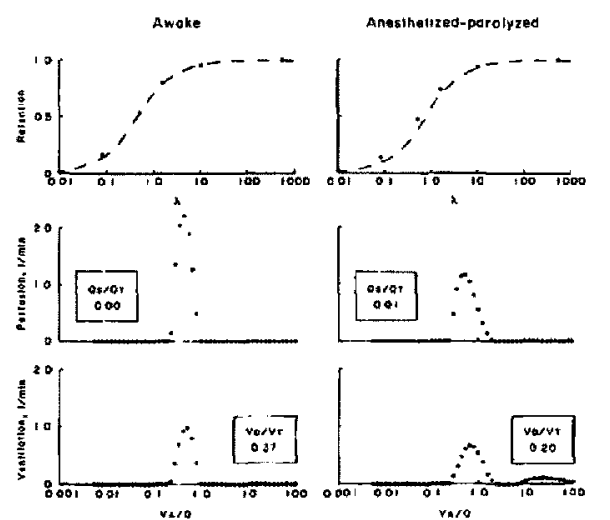

Figure 18 Ventilation to perfusion relationship determined with inert-gas elimination method. Subject was breathing 30 per cent oxygen and studied while in the supine position. Top Paneds. Retention vs. blood:gas partition coefficient for six inert gases. Dashed lines are theoretical retentions for lungs, with homogeneous ventilation-to-perfusion relationship equal to mean ventilation-to-perfusion ratio. Measured retentions are indicated by (\$). Middle and Borton Panels, Distribution of perfusion and ventilation relative to ventilation-to-perfusion ratio. Note increased dispersions of both perfusion and distribution of ventilation after induction of anaesthesia. (From REHDER, $e$ ? at. ${ }^{12}$ By permission from the American Physiological Society.)
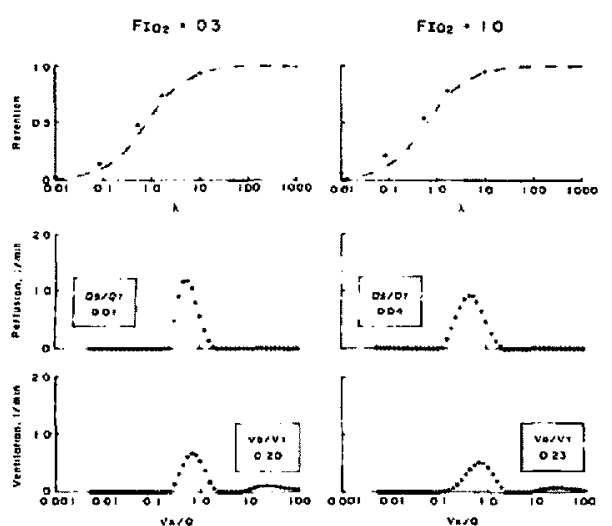

Figure 19 Ventilation to perfusion relationship in anaesthetized-paralyzed subject studied in supine position, once while his lungs were ventilated with 30 per cent and once with 100 per cent oxygen. Coordinates and symbols as in Figure 18. Data were obtained from same subject as in Figure 18. Note increased dispersions of ventilation and perfusion distribution and development of a four per cent right-to-left intrapulmonary shunt. (From ReHDER, et al. ${ }^{12}$ By permission of the American Physiological Society.) breathing of 30 per cent and 100 per cent oxygen in andesthetized-paralyzed subjects. The rightto-left shunt increased during oxygen breathing (Figure 19).

\section{SUMMARY}

Pulmonary gas exchange is disturbed during general anaesthesia; both oxygenation and elimination of carbon dioxide are impaired. The shape of the chest wall alters after induction of anaesthesia-paralysis in recumbent subjects. and its motion during inspiration is also altered. The mechanical properties of lung and chest wall are also affected and FRC may be reduced. Inspired gas distribution changes after induction of anaesthesia-paralysis with mechanical ventilation of the lungs. Distribution of pulmonary blood flow is altered in subjects in the sitting and right lateral decubitus positions, but the distribution is not adjusted to the altered distribution of inspired gas. This results in an increased mismatching of ventilation to perfusion, with development of lung regions that have low and high ventilationto-perfusion ratios. Some lung regions with low ventilation-to-perfusion ratios develop into right-to-left shunt on breathing 100 per cent oxygen.

The following sequence of events probably occurs after induction of anaesthesia-paralysis. The initial effect of anaesthesia seems to be on the shape and motion of the chest wall. This may alter the mechanical properties of both the chest wall and the lung. Intrapulmonary gas distribution is altered secondarily. Pulmonary blood flow distribution. which is primarily determined by gravity, does nol seem to adjust to the altered distribution of inspired gas. Hence, an increased mismatching of ventilation to perfusion develops. This includes the development of lung regions with low ventilation-to-perfusion ratios. These regions may progress into right-to-left shunt during 100 per cent oxygen breathing. The low ventilation-to-perfusion regions and the shunt may both impair oxygenation. The development of lung regions with high ventilation-to-perfusion ratios after induction of anaesthesia-paralysis contributes to the inefficient elimination of carbon dioxide.

\section{RÉSUMÉ}

L'échange gazeux pulmonaire est perturbé au cours de l'anesthésie générale, l'oxygénation et 
l'élimination du $\mathrm{CO}_{2}$ étant toutes les deux détériorées. Chez le sujet couché, la configuration et le mouvement en inspiration de la paroi thoracique changent après l'induction de l'anesthésie avec paralysie musculaire. Les propriélés mécaniques du poumon et de la paroi thoracique sont aussi altérées et la capacité résiduelle fonctionelle peut être diminuée. La distribution des gaz inspirés change sous ventilation artificielle après l'induction de l'anesthésie générale avec paralysie musculaire. La distribution du débit sanguin pulmonaire est altérée chez les sujets assis et en position latérale droite, mais n'est pas ajustée a l'altération de la distribution des gaz inspirés. Ceci conduit au développement de régions pulmonaires avec des rapports ventilation-perfusions soit bas soit élevés; donc, l'inégalité des rapport ventilation-perfusion est augmentée. Dans certaines régions du poumon où ce rapport est bas, des shunts droits-gauches se développent sous ventilation à 100 pour cent d'oxygène. L'induction de l'anesthésie avec paralysie musculaire déclenche probablement la chaine d'événements suivants; I'effet de l'anesthésie semble tout d'abord se manifester au niveau de la configuration et des mouvements de la paroi thoracique. Ceci peut changer les propriétés mécaniques de la paroi thoracique et du poumon. Puis la distribution des gaz inspirés est changêe. La distribution du débit sanguin pulmonaire, surtout influencée par la gravitê, ne semble pas s'ajuster à l'altération de la distribu. tion des gaz inspirés. Il en résulte unc augmentalion des perturbations des rapports ventilationperfusion, avec apparition de régions où le rapport ventilation-perfusion est bas, produisant des shunts droits-gauches sous oxygène à 100 pour cent. Tout ceci peut perturber l'oxygenation. Le développement de régions pulmonaires à rapport ventilation-perfusion êlevé contribue à une élimination inefficace du $\mathrm{CO}_{2}$.

\section{ACKNOWLEDGEMENTS}

This work would not have been possible without the help, advice, and encouragement of my colleagues and friends, Drs. Ward S. Fowler, Robert E. Hyatt, Alan D. Sessler, Joseph R. Rodarte, H. Michael Marsh, Mr. Thomas J. Knopp, and Mr. Bernard P. Gilles. The excellent technical help from Mr. Gerald J. Rach, the fine art work of Mrs. Kathleen A. Street, and the outstanding secretarial help of Miss Carol J. Mickow are all gratefully acknowledged.

\section{REFERENCES}

1. NUNN, J.F. Factors influencing the arterial oxygen tension during halothane anaesthesia with spontaneous respiration. Br. J. Anaesth. 36:327 (1964).

2. NunN, F Bergman, N.A \& Colmman, A.J. Factors influencing the arterial oxygen tension during anaesthesia with artificial ventilation. $\mathrm{Br} . \mathrm{J}$. Anaesth. 37: 898 (1965).

3. Michenfelder, I.D. Fowler. W.S. \& Theye. R.A. $\mathrm{CO}_{2}$ levels and pulmonary shunting in anesthetized man. J. Appl. Physiol. 21: 1471 (1966).

4. Bergman, N.A. Components of the alveolar. arterial oxygen tension difference in anesthetized man. Anesthesiology 28;517 (1967).

5. Marshall, B.E. Conen, P.J. Klingenmaiter, C.H.\& AUkBERG, S. Pulmonary venous admixture before, during, and after halothane:oxygen anesthesia in man. J. Appl. Physiol. 27: 653 (1969).

6. Price, H.L., Cooperman, L.H., Warden, J.C., Morkis, J.J. \& SMITH. T.C. Pulmonary hemodynamics during general anesthesia in man. Anesthesiology 30: 629 (1969).

7. Marsh, H.M.. Rehder. K., Sessler, A.D. \& FOWLER, W.S. Effects of mechanical ventilation, muscle paralysis, and posture on ventilation. perfusion relationships in anesthetized man. Anesthesiology $38: 59$ (1973).

8. Campbell, E.J.M., Nunn, J.F, \& Pecketr. B.W. A comparison of artificial ventilation and spontaneous respiration with particular reference to ventilation-bloodflow relationships. $\mathrm{Br} . \mathrm{J}$. Anaesth. 30: 166 (1958).

9. NunN, J.F. \& HiLl, D.W. Respiratory dead space and arterial to end-tidal $\mathrm{CO}_{2}$ tension difference in anesthetized man. J. Appl. Physiol. 15: 383 (1960).

10. AskroG. V.F., PENDER, J.W., Smith, T.C. \& ECKENHOFF, J.E. Changes in respiratory dead space during halothane, cyclopropane, and nitrous oxide anesthesia. Anesthesiology 25: 342 (1964).

11. KaIn, M.L. Panday, J. \& Nunn. J.F. The effect of intubation on the deadspace during halothane anaesthesia. Br. J. Anaesth. 41: 94 (1969).

12. Rehder, K. KNopP, T.J. Sessler, A.D. \& DiDIER, E.P. Ventilation-perfusion relationship in young healthy awake and anesthetized-paralyzed man. (Accepted for publication, J. Appl. Physiol.)

13. Mil.ic-EMil, J., Henderson, J.A.M., Dolovich, M.B., Trop, D. \& Kaneko. K. Regional distribution of inspired gas in the lung. $J$. Appl. Physiol. 21 : 749 (1966).

14. West, J.B., Dollery, C.T. \& Naimark, A. Distribution of blood flow in isolated lung; relation to vascular and alveolar pressures. J. Appl. Physiol. 19: 713 (1964).

15. SNow, J. On chloroform and other anaesthetic agents: their action and administration. John Churchill, London (1858).

16. Rehder, K.. Hatch, D.J. Sessl.er, A.D.. MARSh, H.M. \& FowLER, W.S. Effects of general anesthesia, muscle paralysis, and mechanical ventilation on pulmonary nitrogen clearance. Anesthesiology 35: 591 (1971).

17. Rehoer, K., Hatch, D.J., Sessiler, A.D. \& FOWLER, W.S. The function of each lung of anesthetized and paralyzed man during mechanical ventilation. Anesthesiology 37: 16 (1972). 
18. LiLl.INGTON, G.A., FowLER. W.S. MHLLER, R.D. \& HELMHOLZ, H.F., JR. Nitrogen clearance rates of right and left lungs in different positions. J. Clin. Invest. 38: 2026 (1959).

19. Agostoni. E. Mechanics of the pleural space. Physiol. Rev, 52: 57 (1972).

20. Rehder. K. SEssler. A.D. \& Rodarte. J.R. Regional intrapulmonary gas distribution in awake and anesthetized-paralyzed man. J. Appl. Physiol. 42: 391 (1977).

21. Froese. A.B. \& Bryan, A.C. Efrects of anesthesia and paralysis on diaphragmatic mechanics in man. Anesthesiology 41 : 242 (1974).

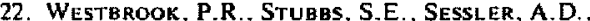
REHDER, K, \& HYATT, R.E. Effects of anesthesia and muscle paralysis on respiratory mechanies in normal man. J. Appl. Physiol. 34: 81 (1973).

23. Rehder, K., Sessler. A.D. \& Marsh, H.M. Gencril anesthesia and the lung. Am. Rev. Respirat. Dis. 112: 541 (1975).

24. Rehder, K., Sittipong, R. \& Sessler, A.D. The effects of thiopental-meperidine anesthesia with succinylcholine paralysis on functional residual capacity and dynamic lung compliance in nomal sitting man. Anesthesiology 37: 395 (1972).
25. Grimby, G.. Hedenstierna, G. \& Löfström, B. Chest wall mechanies during artificial ventilation. J. Appl. Physiol. 38: 576 (1975).

26. Tusiewicz. K., Bryan. A.C. \& Froesk, A.B. Contributions of changing rib cage-diaphragm in. teractions to the ventilatory depression of halothane anesthesia. Anesthesjology 47: 327 (1977).

27. Schmid, E.R., KNopP. T.J. HYATt, R.E. \& REHDER, K. Chest wall motion in anesthetized supine dogs (unpublished data).

28. Rehder, K., Knopp. T.J. \& Sessler, A.D. Regional intrapulmonary gas distribution in awake and anesthetized-paralyzed prone man. J. Appl. Physiol.: Respirat. Environ. Exercise Physiol. 45: 528 (1978).

29. LANDMARK, S.I., KNOPP, T.J., Rehder. K. \& SESSler, A.D. Regional pulmonary perfusion and $\dot{V} / Q$ in awake and anesthetized-paralyzed man. J. Appl. Physiol.: Respirat. Environ. Exercise Physiol. 43: 993 (1977).

30. DANTZKer, D.R., WAGNer, P.D. \& West, J.B. Instability of lung units with low $\dot{V}_{A} / \dot{Q}$ ratios during $\mathrm{O}_{2}$ breathing. J. Appl. Physiol. 38: 886 (1975). 